\title{
Experiências ambientais de uma prática pedagógica interdisciplinar na Vila de Itaúnas, Conceição da Barra, ES
}

\author{
Environmental experiences of an interdisciplinary pedagogical practice in Vila of Itaúnas Conceição da Barra, ES \\ Rosiane Lima Demoner', Nadja Valéria dos Santos Ferreira², Soler Gonzalez ${ }^{3}$ \\ ' Mestranda Profissional em Tecnologia Ambiental - FAACZ \\ ${ }^{2}$ Doutora em Educação - UFES \\ ${ }^{3}$ Doutorando em Educação - UFES
}

\begin{abstract}
Resumo
O presente artigo relata experiência pedagógica realizada na instituição pública de ensino "EMEF. Eloy Miranda", localizada no município de Fundão, no Estado do Espírito Santo, com os alunos do 7a ano, tendo início no ano de 2010 e continuidade em 2011. Objetivou-se propiciar aos alunos reconhecimento e vivências de experiências pedagógicas e ambientais, para problematizar os principais pontos de fragilidade e de potencialidade, assim como as formas de resistências assumidas na atualidade e na vida cotidiana dos sujeitos que acompanharam e ainda estão vivenciando as causas dos impactos decorrentes do desmatamento e do uso indevido do solo. Para realizar o trabalho foi desenvolvido um diagnóstico social, cultural e ambiental realizado por meio um estudo de campo envolvendo a cidade de Fundão e a Vila de Itaúnas, sendo registradas as conversas e entrevistas com os moradores locais num Diário de Campo, contemplando de forma interdisciplinar. A experiência pedagógica possibilitou aos alunos conhecer na Vila de Itaúnas os reflexos dos desastres ambientais e refletir suas atuais ações/ atitudes para que os desastres ambientais e sociais do seu município sejam minimizados, além de propiciar a interação com a sabedoria popular, explorando a sensibilidade do contato direto dos alunos e a vivencia de uma nova cultura, história e saberes construídos ao longo dos anos. E decorrente a importância da transversalidade de saberes, atualmente inserida no Projeto Político Pedagógico da escola.
\end{abstract}

Palavras Chave: Educação Ambiental, Itaúnas, Fundão, Escola.

\begin{abstract}
This paper reports on the pedagogical experiment performed in the public university "EMEF. Eloy Miranda ", located in the municipality of Fundão, in Espírito Santo, with students of 7th year, starting in 2010 and continuing in 2011. The objective was to provide students with experiences and recognition of teaching experience and environmental, to discuss the main points of fragility and potential, as well as forms of resistance taken today and everyday life of the subjects who followed and are still experiencing the causes of impacts of deforestation and improper land use. To perform the work developed a diagnostic social, cultural and environmental carried through a field study involving the town and village of Fundão Itaúnas being recorded conversations and interviews with locals in a Field Journal, contemplating in an interdisciplinary way. The teaching experience allowed students to meet in the Village of Itaúnas reflections of environmental disasters and reflect their current actions / attitudes to the environmental and social disasters of its municipality are minimized, besides providing interaction with popular wisdom, exploring the sensitivity of direct contact of students and experience a new culture, history and knowledge built up over the years. And due to the importance of mainstreaming knowledge, currently inserted in Political Pedagogical School Project. Keywords: Environmental Education, Itaúnas Fundão School
\end{abstract}




\section{INTRODUÇÃO}

Nos últimos anos vem se intensificando a preocupação com a questão ambiental e a escola emerge como espaço de convivência, assim como a comunidade com toda a potência da vida cotidiana, contribuindo com práticas interdisciplinares relacionando as dimensões éticas, estética, política e ontológica dos sujeitos envolvidos no processo de aprendizagem, envolvendo assim os diferentes níveis e modalidades de ensino, desde a Educação Infantil ao Ensino Médio. A aposta aqui é que nesse processo complexo que englobam espaços, tempos e sujeitos na educação, e especialmente no campo da Educação Ambiental (TRISTÃO, 2004; SATO, 2001), as experiências ambientais ganham um matiz problematizador e ontológico diante das formas pensadas, planejadas e executadas para atingir os objetivos esperados com a atividade que será comentada neste trabalho.

Rodrigues (2008, p.171) propõe:

[...] abordar a dimensão ecológica na escola envolve as contradições que emergem do cotidiano e que se configuram em linguagens e concepções evidenciadas na escola, [...] Promover a aprendizagem utilizando-se de estratégicas que venham contribuir com o cotidiano dos indivíduos significa caminhar em busca de um novo éthos nas relações entre os seres humanos e o meio ambiente, de modo que possam se relacionar com mais solidariedade e que seus valores, atitudes e comportamentos práticos estejam direcionados para a qualidade de vida e cooperação. [...]

Devido aos fatos históricos ocorridos na Vila de Itaúnas, e a necessidade de incentivar os discentes à uma nova postura diante das questões ambientais, a equipe pedagógica e o corpo docente da EMEF "Eloy Miranda", desenvolveram um diagnóstico social, cultural e ambiental realizado por meio um estudo de campo envolvendo a cidade de Fundão e a Vila de Itaúnas com objetivos de reconhecer e vivenciam experiências pedagógicas e ambientais para problematizar os principais pontos de fragilidade e de potencialidade, assim como as formas de resistências assumidas na atualidade e na vida cotidiana dos sujeitos que acompanharam e ainda estão vivenciando as causas dos impactos decorrentes do desmatamento e do uso indevido do solo. "A Educação Ambiental é uma das dimensões educativas e formativas que permearam a concep- ção e o desenvolvimento das ações pedagógicas e interdisciplinares dessas experiências ambientais na complexidade" (MORIN, 2007).

A instituição de ensino que foi protagonista desta experiência pedagógica e ambiental está localizada na cidade de Fundão, ES, município próximo a Região Metropolitana da Grande Vitória e que nos últimos anos teve parte da vegetação de Mata Atlântica do seu território substituída, principalmente nas margens e adjacências do Rio Fundão, por áreas de agricultura, pecuária, residências e pastagens, mesmo sendo esse ecossistema considerado como "Área de Preservação Permanente (APP)", conforme o Código Florestal (Lei n. $\left.{ }^{\circ} 4.771 / 65\right)$. Como consequência de tais alterações podemos na atualidade constatar a presença de residências construídas de maneiras irregulares, provocando erosão e assoreamento do rio e desencadeando outros impactos no modo de vida das populações ribeirinhas, como é o caso dos registros das constantes enchentes no município.

A Vila de Itaúnas é um dos Distritos de Conceição da Barra, localizada ao norte do Espírito Santo, região litorânea onde há formação de dunas. Segundos relatos de moradores locais

nos anos 50 a 70 a Vila de Itaúnas passou por um processo de retirada das vastas áreas com mata nativa desencadeando um processo permanente e ainda em ação que provocou o soterramento da antiga vila que se viu obrigada a se instalar no outro lado do Rio Itaúnas. Tal processo, que ainda ocorre, ocasionou perdas, mas desencadeou também formas de resistências na população, agora habituada com a nova Vila, mas cheia de lembranças e histórias que povoam o imaginário local.

\section{METODOLOGIA}

O projeto emergiu de uma experiência pedagógica vivenciada em uma escola privada denominada IES, localizada na cidade da Serra/ ES. No ano de 2010, essa mesma experiência foi adaptada à realidade local e teve inicio ao projeto na instituição pública, envolvendo alunos do $7^{\circ}$ ano dos turnos matutino e vespertino. A equipe pedagógica elaborou um material didático estimulando que os estudantes produzissem seus próprios registros e experiências num Diário de Campo, traduzindo assim, como a experiência ambiental de visitar e conhecer a Vila de Itaúnas potencializou nos sujeitos envolvidos reflexões envolvendo as formas de relações desencadeadas 
na atualidade pela nossa sociedade do consumo.

Os sujeitos envolvidos tiveram a oportunidade de compartilhar entrevistas e conversas (MATURANA, 1999) com moradores locais, por meio de grupos de pesquisa que saiam pela Vila, orientados pelos docentes, para perceberem o modo de vida e de reinvenção da vida por meio das formas de resistências cotidianas demandadas pelas transformações antrópicas na paisagem do Parque de Itaúnas.

No Parque Estadual de Itaúnas assistiram a uma palestra educativa proferida por monitores do local, ressaltando as histórias, as lendas, as formas de vida e os sítios arqueológicos da antiga vila e das tribos que viviam na região, tudo isso demonstrado por fotos antigas e artefatos provenientes de pesquisas arqueológicas no parque.

As atividades e experiências pedagógicas e ambientais dessa visita foram finalizadas com o percurso da trilha ecológica que relata fragmentos da história da população local, trilha essa que percorre o "mar de dunas", as ruínas da antiga vila, hoje soterrada, e, os Sítios Arqueológicos das antigas tribos indígenas.

O retorno à escola foi marcado por momentos de convivência e experiências das vivências que extrapolaram as fronteiras aparentemente fixas das áreas de conhecimento. Foram contempladas produções e traduções dessas experiências pedagógicas e ambientais com o auxilio das novas tecnologias (Laboratório de Informática Educacional) resultando na produção artística de materiais didáticos e informativos, maquetes com materiais alternativos com a temática da Vila de Itaúnas e mural demonstrativo das realidades pesquisadas. Ressaltando assim a interdisciplinaridade presente no campo da Educação Ambiental e o cuidado a todas as formas de vida (BOFF, 1999).

\section{RESULTADOS E DISCUSSÃO}

A prática pedagógica possibilitou aos estudantes e professores uma análise entre as duas realidades, trocas de informações e conhecimentos adquiridos sobre o local visitado permitindo uma reflexão da necessidade da preservação e conservação do ambiente, tendo visão que as ações sofridas pela população da antiga Vila foram acarretadas pela falta de conscientização ambiental e destruição do seu meio. Propiciando a aprendizagem fora dos limites físicos da escola, sala de aula e livros didáticos, explorando a sensibilidade do contato direto dos alunos com a população local e a vivencia de uma nova cultura, história e saberes construídos ao longo dos anos.

Podendo assim, refletir suas atuais ações/ atitudes para que os desastres ambientais e sociais local sejam minimizados, principalmente em relação ao rio Fundão, que a cada dia está reduzindo a quantidade de água e assoreamento que não permite a vazão da água pluvial.

Quando foram perguntados sobre o que representou a visita pedagógica os alunos, declararam: "Foi um passeio legal e muito importante para mim e pra todos que participaram." "Eu achei muito boa, aprendi muito sobre Itaúnas, nunca tive a oportunidade de visitar a Vila." "Para mim o passeio a Vila de Itaúnas foi uma viagem de aprendizado e diversão." "O passeio a Itaúnas foi muito bom, e percebi que se nós não cuidarmos do meio ambiente podemos também sofrer algumas consequências como eles." "Foi muito legal e com isso eu aprendi muitas coisas legais, a história e sobre as tartarugas, até que eu queria ir lá de novo." "Foi um jeito novo de aprender interagindo com os moradores da Vila de Itaúnas." "Para mim foi uma grande oportunidade de aprendizado, conhecer novos lugares e se divertir com os meus amigos e professores."

Entre os registros de imagens que vivenciaram frisaram que o que chamou mais atenção foram as dunas, o tronco da árvore no centro da Vila e o Sítio Arqueológico.

Neste contexto, o estudo da percepção ambiental permitiu a construção de sujeitos-atores capazes de repensar seus valores, ações e elaborar ações que visem mudanças mais efetivas para a sustentabilidade socioambiental. Entretanto, a prática pedagógica é uma das propostas que permite a melhoria da qualidade do ensino aprendizado no campo da Educação Ambiental, que se recomenda o seu desenvolvimento e atualizações das atividades propostas nos anos subsequentes.

$\mathrm{O}$ projeto permaneceu em atividade em 2011 e diante dos resultados obtidos nos dois anos realizados, atualmente está formalmente inserido no Projeto Político Pedagógico da instituição o que permite o seu desenvolvimento nos anos letivos subsequentes, denotando assim a potência política e ética dessas ações que inicialmente se apresentaram como atividades complementares e pontuais e, agora reconhecidas como permanentes e processuais, ganhando assim uma legitimação e aceitação da comunidade escolar no que se refere à Educação Ambiental nesse processo permanente de formação dos sujeitos. 


\section{AGRADECIMENTOS}

A realização deste estudo envolveu um grande quantitativo de pessoas. Pessoas estas importantes para o desenvolvimento e conclusão, sendo: os estudantes dos $7^{\circ} \mathrm{s}$ anos do ano de 2010 e 2011, os docentes, pedagogos e diretora escolar da EMEF "Eloy Miranda", que participaram com dedicação, carinho e incentivo em todos os momentos.

Aos pais que apoiaram e acreditaram na proposta pedagógica do projeto, permitindo seus filhos a participarem e ampliarem seus horizontes quanto às questões ambientais.

A equipe pedagógica do Ensino Fundamental II da Secretaria Municipal de Fundão, ES - SEMED, pelo apoio, participação e auxiliar no que foi preciso para a realização do projeto.

\section{REFERÊNCIAS BIBLIOGRÁFICAS}

BOFF, L. Saber cuidar, Ética do humano - compaixão da terra. Petrópolis, Rio de Janeiro: Vozes, 1999.

MATURANA, H. A ontologia da realidade. Belo Horizonte: Editora da UFMG, 1999.

MORIN, E. Introdução ao pensamento complexo. Porto Alegre: Ed. Sulina, $3^{\text {a }}$ edição, 2007.

RODRIGUES, L. D. Conhecimento e Ressignificação: A prática pedagógica em Educação Ambiental. In: BAGGIO, A; BARCELOS, V. (orgs.) Educação ambiental e complexidade: entre pensamentos e ações. Santa Cruz do Sul: EDUNISC, 2008.

SATO, M. Apaixonadamente pesquisadora em educação ambiental. Revista Educação Teoria e Prática, Rio Claro, v. 9, n. 16/17, p. 24-35, 2001.

TRISTÃO, M. A educação ambiental na formação de professores: redes de saberes. São Paulo: Annablume, 2004. 